\title{
The Lexical Features of English Advertisement
}

\author{
Yanping Fan \\ College English Department \\ Kaifeng University \\ Kaifeng, China \\ Fanyp286@163.com
}

\begin{abstract}
With the rapid development of economy, the world is thick with commercials and advertisements. The aim of advertisements is to persuade the potential customers to buy their product by means of impressive words, so advertisers are very careful about the choice of words. In order to compete with many other similar advertising messages and achieve high advertising effectiveness, advertisers always use various linguistic devices to catch readers' attention, arouse their desire and induce their action. In this paper, the lexical features of advertisement are analyzed from the following aspects: the use of homophones, adjectives, interrogatives, personal pronouns, neologisms and compounds.
\end{abstract} feature

Keywords- English advertisement; linguistic device; lexical

\section{INTRODUCTION}

Advertisement, as a means of effective sales promotion, is used to disseminate information, acquire its image and stimulate consumption through advertising language. In order to arouse readers' interest and curiosity and achieve high advertising effectiveness, advertisement must be noticeable and readable, the language must be brief, novel, impressive and persuasive. Just as Jonathna Swift said, "proper words in proper places make the true definition of a style". So the choice of words in advertising is very cautious and skillful. The present study attempts to examine the lexical features of advertisement which include: using new form of the spelling of a word to attract readers; frequently using monosyllabic verbs and adjectives to express the information and enhance the effect of language expression; using pronouns for purpose of concision.

\section{THE LEXICAL FEATURES OF ENGLISH ADVERTISEMENT}

\section{A. Use of Homophones}

Advertisers always use homophones to make advertisements lively and full of humor. For example:

(1) Don't catch a cold, catch a plane to Fiji.

Don't get the flu this winter, be the ones who flew to Fiji.

Here the use of homophones "Flu" (the abbreviation of influenza) and "flew" (past form of fly) has a magic effect on the advertisement, which aims to warn people not to catch a cold and remind them of taking a tour by plane to Fiji which has picturesque scenery and pleasant weather. In Fiji you may free from catching a cold. Another example:
(2) "VIP" Anatomical Comfort

Variable Impact Pressure Sole

Generally, VIPs means "Very Important Persons", but in this advertisement VIPs refers to "Variable Impact Pressure Sole". The use of homophone can pique readers' vanity and incite them to buy the product.

\section{B. Use of Monosyllabic Verbs}

As monosyllable can make advertisement clear and concise and easily understood, accessible monosyllabic verbs are always used in advertisement instead of those rarely used abstruse multisyllabic verb. Let's take car sales advertisement for example:

\section{(3) Buy One, Get More.}

The use of two monosyllables "buy" and "get" instead of "purchase" and "obtain" vividly portrays the interaction between advertisers and consumers. These simple and informal verbs make the readers feel memorable and intimate, thus effectively stimulate their interest. And the word "get" here connotes the meaning of "obtaining something without having to pay the money". The advertiser tries to convince readers that he offers help with its product instead of simply selling it out. In advertising, these simple words can win the consumers by their exact, effective expression and a kind of closeness. The most frequently used monosyllabic verbs in advertising are: buy, get, make, like, try, feel, taste, look, keep, need, see, know, etc.

\section{Wide Use of Adjectives and Their Comparative and Superlative Forms}

The adjectives used in ads can be divided into two groups: descriptive adjectives in object description and evaluative adjectives giving the advertiser's subjective comments. And adjectives are effective tools to convince the readers that the product advertised is second to none. A number of adjectives in advertising display the product extra value and make the advertising eye-catching. They are used to warmish the commodity and redecorate the advertising to stimulate the readers' desire of buying. As Leech (1966) observed, "Advertising language is marked by a wealth of adjective vocabulary". So advertisers often use them to promote the commodity and persuade the potential consumers. More importantly, they help readers establish an affirmative attitude towards the products. Such adjectives as new, good, best, free, full, fine, easy, bright, delicious, crisp, fine, tall, 
big, rich, wonderful, etc. are often put to use in advertising. See the following example:

(4) Healthy skin is: Firm. Rich in moisture. Fewer lines. Even-toned. Supple. Smooth.

In this tempting advertising of skin care product, adjectives make up half of the whole advertising. These adjectives give a complete description of the function and characteristic of the product and build a pleasant picture in readers' mind. The temptation aroused by this vivid description of the product is hard to resist.

In addition, advertisers tend to use comparatives and superlatives to indicate the excellent quality of their product or service. The connotation of the comparative and superlative form of adjective is very clear while its denotation is ambiguity and vague and there is hardly any objective standard to measure them by, so in advertising, advertisers would use many vague and subtle comparisons to contrast its promoted commodity with other brands. By doing so, advertisers raise awareness of their products and avoid building up one's commodity image by condemning other brands as well, and also leave consumers a good impression of businesses' consistent improvement and perfection of their products. For example:

(5) Of American's best-tasting gums. Trident is sugar-free.

Here are two tricks: one is that the ad indirectly puts the Trident among "American's best-tasting gums"; the other is that the advertiser deliberately omits (but obviously implying) the word "only". Trident doesn't say that other gums are not sugar free, but with the word "only" so heavily implied, the ad actually implies that Trident is the best-tasting gum. The superlative describes the uniqueness of the products.

Advertisers also use comparisons to fulfill consumers' expectation on the commodity, as:

(6) Beauty wise, value wise, you can't buy better than Rimmel.

The comparative here is used to show the products' distinctive quality.

From the above, we can see that comparatives and superlatives occur to highlight the advantage of a certain product or service. They focus on the difference of the product or the service and enhance persuasion at the same time. Customers always are inclined to know the difference by comparing sensitively.

\section{Use of Interrogatives}

In making an advertisement, advertisers sometimes use interrogative to produce a presupposition effect, through which the high quality and utility is indirectly expressed. The use of interrogatives shows the advertiser is confident of its product quality and function which leave the consumer a wild imagination of the various right choices and incite them to attempt to buy. For example:

(7) Which of these continental quilt patterns will suit your bedroom best?

From which consumers can presupposes : a). All these continental patterns will suit your bedroom.

b).One of these continental quilt patterns will suit your bedroom better than the otherUnits

\section{E. Frequent Use of Personal Pronouns.}

In advertising, advertises are more likely to use personal pronouns, especially "you" and "we", to make the language more warm and friendly in tone, build a closer relationship between the advertiser and the reader and strengthen its appeal to the readers. In a word, pronouns of the first and second person create a friend-like intimate atmosphere to move and persuade the readers. And the use of "we" also leaves the reader an impression that the advertisers are obedient and provide good service with him. Through the use of personal pronouns, the advertisers try to convince the reader that all the products and service they offer are out of the consideration of his particular needs and benefits, and hence persuade the reader to do the purchase. There is a GM ad going like this:

(8) Because quality over time means so much for you, it means even more to us.

In the past several years, we have turned our company inside out to deliver lasting quality to you.

Today we're building quality you'll experience from the first months you own your new car or truck through the years that it's part of life.

In this example, the use of personal pronoun "we" and "us" makes the reader feel he can, as it were, see and hear the advertiser in action while the use of "you" expresses the reader's needs, desires, and hopes more effectively, which makes the reader feel that he is the right person the advertisers care about and are eager to help. As a result, "one cannot help being deeply impressed by GM's earnest concern for the consumer in terms of the lasting quality of their cars and trucks". And together with the pronoun "we", the ad gives the reader the impression that he can just enjoy the comfort and leisure, and leave the work to the advertisers.

\section{F. Selection of Loanwords and Interjections}

Loanwords are often used in advertisement to indicate the high quality of the product and its exotic features and styles, these distinctive loanwords greatly attract the customer and satisfy their curiosity and requirement on fashion. French and Spanish are very popular in English ads. For example:

\section{(9)Wow! TE ATATU SOUTH}

Hot! Hot! Hot! Only $\$ 110,000$

The interjection "Wow" explains the price of the house is surprisingly low. Loanwords are frequently used in advertisement to show the specialty and high quality of the product and attract the readers' attention. Another example of loanword in ads:

(10) Order it in bottles or in cans.

Perrier...with added je ne sais quoi

In this French soft drink ad, the use of the French word focuses on the authentic French drink. As many products 
advertised are imported from other countries, advertisers sometimes deliberately put some foreign words into the advertising text to make the product appear exotic and hence more appealing.

\section{G. Use of Coinage}

Coinage is a method to create new words. The use of coinage is one of the most important features in advertising. New words or phrases created by means of imitation are often seen in English advertisement. The new concept of advertisement is epitomized by the creation of new terms, which give the words new meaning. Since newly coined words and phrases may suggest that the product advertised possesses peculiar qualities as well as the value of novelty, advertisers, in order to attract readers' attention, try all sorts of dodges to create new strange words to make the implication understood in the light of some phonetic basis, semantic basis and syntactic basis between coinage and prototype words and some relevant association, that is the readers' original vocabulary and semantic knowledge, to make the ad fresh, lucid, lively and attractive. Advertisers always use the following ways to coin new words.

\section{1) Addition and subtraction}

Add or subtract some letter of the word to make its meaning changed or extensive. For example: A seller of an American chain called "payle\$" uses the variation of "pay" and "less" to tell customers that goods here are cheap and you pay less dollars in this shop. The new word is short, clear and easy to remember. Another example:

(11) The Orangemostest Drink in the world.

This is an advertisement of some drink, in which the coined word "Orangemostest" is equal to "Orange + most +est". "Most" and "est" both stand for superlative, when they are used with "Orange", the newly coined word brings a thrilling effect and the stressed high quality and purity of the orange juice leaves people a wild imagination and a strong memory in readers' mind.

2) Compounding. Coin new words according to word building. For example: cheeseburger and fishburger are coined from 'hamburger'.

3) Misspelling. Coin new words according to homophone. In order to make advertisements lively and humorous, advertisers always give the homophone a new spelling on the basis of the features of homophone, which can stimulate the customer and leave them a good impression well within the memory of the customer. For example:

(12) We Know Eggsactly How to Sell Eggs.

Here "eggsactly" is the homophonic spelling of "exactly". In order to make the product magic and give readers an indescribably wonderful feeling, advertisers cheat by using the morphologically corresponding word "eggs" instead of "ex" so as to make it witty and readable. Another example:

(13) Have a nice trip, buy-buy!

This is an advertisement in front of a duty free shop at Heathrow airport of London. In saying bye-bye to travelers, advertisers use "buy-buy", the homophonic spelling of "byebye" to remind them to buy some gifts in departing. The travelers are overwhelmed with admiration for advertiser's clever idea. And the homophonic spelling deepens their impression once they try to rectify it.

The wide use of coinage is that by rationally and deliberately violating the language norm, advertisers try to activate readers' creative thinking and make them reason the real communication significance to reach wonderful communication effect in the course of comparing the typical features between the new feature and the register or context.

\section{H. Flexible use of Compounds}

A compound is composed of two or more words or morpheme which may convey unusual meaning and so arouse readers' rich associations. Because of their expressiveness and brevity, advertisers often use them to make the language concise and vivid, easy to understand and remember and give readers an intuitive deep impression.

As we all know, different compounds have different effect. Some give a vivid and appropriate description of the features of the product while the others describe the remarkable function of the product in a humorous and witty way. The frequently used forms of compound are: 1) $n+n$ : audio-visual, 2) n+a.: snow-white, 3) n+v-ed: milk-flavored, 4) n+v-ing: word-processing, 5) a.tn: multi-function, 6) a.+ving: long-standing, 7) a.+prep+v: easy-to-go, 8) a./ad.+ved: warm-hearted.

In addition, advertisers sometimes use suffix, affix and acronym in advertisement. And acronym is widely used in English advertisement because it can cut down advertising cost, save space and simplify replication. Such advertisements become deepened in the impression of the customer. The most commonly used affixes include super-, ex-, ultra- and auto. For example: superstar.

\section{CONCLUSION}

Brilliant advertisements root in remarkable product, but its persuasion and allure is realized by refining upon the language. The lexical choice of words in advertisement is an art. Therefore, in advertising, advertisers are often careful about the choice of words to make it more competitive.

\section{REFERENCE}

[1] Chen Xin. A Guide to English-Chinese Translation of Stylistic Varieties[M]. Beijing : Beijing University Press, 1999: 212.

[2] Ding Shude . Chinese-English Advertisement Practical Handbook[M]. Tianjin : Tianjin Science Press, 1995: 304-306.

[3] Xu Youzhi. Modern English Stylistics[M]. Kaifeng : Henan University Press, 1992 : 125-129.

[4] Qin Xiubai。 Elementary English Stylistics[M]。Hunan : Hunan Education Press, 1986:200-203.

[5] Leech, G. English in Advertising [M]. London: Longman, 1966.

[6] Ren Jingsheng. On English Nonce Words: Formation Ways, Rhetoric Features and Translation[J]. Chinese Translators Journal(1): 44-47.

[7] Yu Jianhua. The Acceptability of the "Unacceptable" Spelling in English and Its Rhetorical Function[J]. Journal of Foreign Language, 1995(2): 60-68.

[8] Fan Yanping. The Lexical Magic of English Advertisement[J]. Journal of Kaifeng University, 2003(3). 